\title{
Spatial-temporal Characteristics of Land Use Intensity of Coastal Zone in China During 2000-2010
}

\author{
DI Xianghong ${ }^{1,2,3}$, HOU Xiyong ${ }^{1}$, WANG Yuandong ${ }^{1,2}$, WU Li $^{1,2}$ \\ (1. Yantai Institute of Coastal Zone Research, Chinese Academy of Sciences, Yantai 264003, China; 2. University of Chinese Academy of \\ Sciences, Beijing 100049, China; 3. College of Resources, Environment and Planning, Dezhou University, Dezhou 253023, China)
}

\begin{abstract}
Based on remote sensing and GIS techniques, land use maps in 2000, 2005 and 2010 in China's coastal zone were produced, and structural raster data of land use were further generated to calculate land use intensity comprehensive index (LUICI) for analyzing land use spatial-temporal characteristics at $1 \mathrm{~km}$ scale. Results show that: 1) from the perspective of spatial patterns of landforms at a macro scale, there is a significant difference in land use intensity between the north and the south of China's coastal zone. Hotspots of changes mainly concentrated in metropolitan areas, estuaries and coastal wetlands; 2) elevation is an important factor that controlling land use spatial patterns at local scale. Land use intensity is much higher within areas below the elevation of $400 \mathrm{~m}$ and it decreased significantly as the elevation increasing; 3) there is a significant land-ocean gradient for land use intensity, which is low in island and near-shore areas, but high in the regions that 4-30 km far away the coastline because of much intensive human activities; however, in recent decades land use intensity had been promoted significantly in low near-shore area due to extensive sea reclamations; 4) significant differences of land use intensity were also found among provincial administrative units. A rising trend of land use intensity was found in provincial-level administrative units from 2000 to 2010. To sum up, elevation, land-ocean gradient, socio-economic status and policy are all influencing factors to the spatial patterns and temporal variations of land use intensity in China's coastal zone.
\end{abstract}

Keywords: coastal zone; land use intensity; land use intensity comprehensive index (LUICI); spatial pattern; elevation; land-ocean gradient

Citation: Di Xianghong, Hou Xiyong, Wang Yuandong, Wu Li, 2015. Spatial-temporal characteristics of land use intensity of coastal zone in China during 2000-2010. Chinese Geographical Science, 25(1): 51-61. doi: 10.1007/s11769-014-0707-0

\section{Introduction}

Coastal zone is a high complex region on the earth, which is situated on the multi-interface of ocean, land, air, and biosphere. In this region, ecosystem with high productivity and high economic assets provides breeding ground, nest site and food habitat for birds, fish, shellfish and other wildlife (Beatley et al., 2002). It has high levels of socio-economic development and high population density, it homes about $60 \%$ of the world's population (Field et al., 2002); however, under the background of global climate change and sea level rising, the ecosystem and environment are much fragile in the coastal zone. Therefore, it has become an important 'window' on the earth to global change researches. Multidisciplinary researchers worldwide have pay more and more attentions to the coastal zone in recent years, especially to coastal land use changes (Hadley, 2009; Mattheus et al., 2010; Teixido et al., 2010; Hepcan et al., 2011; Käyhkö et al., 2011). Land-Ocean Interactions in the Coastal Zone (LOICZ) is a core project focusing on key problems of the global change research, and high-

Received date: 2013-09-13; accepted date: 2014-01-24

Foundation item: Under the auspices of Strategic Priority Research Program of Chinese Academy of Sciences (No. XDA05130703),

Knowledge Innovation Program of Chinese Academy of Sciences (No. KZCX2-YW-224), 2020-Planning Project of Yantai Institute of Coastal Zone Research of Chinese Academy of Sciences (No. Y254021031-6)

Corresponding author: HOU Xiyong. E-mail: xyhou@yic.ac.cn

(C) Science Press, Northeast Institute of Geography and Agroecology, CAS and Springer-Verlag Berlin Heidelberg 2015 
lighted the coastal land use changes and environmental effects in its new phase of implemental targets in 2003 (Kremer et al., 2005).

Land use intensity is proposed to describe the width and depth of land resources development and the intensive level of land resources. It reflects not only the natural attribute of land resources, but also the comprehensive effect that the natural environment and human activities impact on land resources. Therefore, land use intensity is a most important part of land use and land cover change (LUCC) research (Zhuang et al., 1999; Lambin et al., 2000; Liu et al., 2003). At present, a large number of direct and indirect researches about land use intensity have been carried out at the regional, national and global scales. The relevant researches can be summarized as follows. 1) Quantitative description of land use intensity and its change by the category index method (Wang et al., 2010; Zhou et al., 2011; Quan et al., 2013). 2) Quantitative analysis of influence factors or driving mechanism for the pattern and change of land use intensity (Wang, 2000; Cui et al., 2011). 3) Revealing the spatial-temporal characteristics of land use intensity by mathematical models (Zhuang and Liu, 1997; Ferdous and Bhat, 2013). 4) Investigating the ecological effects of land use intensity changes (Bierschenk et al., 2012; Krausmann et al., 2013; Li et al., 2013; Macchi et al., 2013). However, researches focused on spatial-temporal dynamics of land use intensity in China's coastal zone have not been reported so far.

The coastal zone in China covers across more than 20 latitudes, including temperate, subtropical and tropical climate zones from north to south (Hou and $\mathrm{Xu}, 2011$ ) and its mainland coastline extends about $1.8 \times 10^{4} \mathrm{~km}$, which endows China with very predominant geographical advantages. Therefore, since the beginning of the 'Reform and opening-up' policy in 1978, the coastal area in China has been witnessed very rapid social-economic developments and much prominent economic vitality in the world. However, the rapid industrialization and urbanization, the immoderate sea reclamation and the irrational exploitation of natural resources have exerted enormous pressures on land and waters, biological resources, natural environment and ecosystems in China's coastal zone. At present, much more attentions have been paid to the land use change studies in China's terrestrial regions and a few studies have been reported focused on coastal zone at small or medium scale.
Scarcely any studies about recent land use change in China's coastal zone at macro or national scale could be found.

Therefore, we created land use classification maps in 2000, 2005 and 2010 in China's coastal zone based on remote sensing and GIS techniques, and generated corresponding land use intensity comprehensive index (LUICI) maps at $1 \mathrm{~km}$ scale to analyze the spatialtemporal characteristics of land use intensity. The findings of this paper will not only constitute the basis for a more profound exploration on the characteristics of land use change in China's coastal zone, but also provide possibilities to improve the ability of integrated management of coastal zone.

\section{Materials and Methods}

\subsection{Study area}

Currently, there is not a uniformly accepted standard for the scope of coastal zone, and every country or region has its own definition. In this paper, we defined it as the coastal zone of China's mainland and offshore islands, involving Shanghai and Tianjin municipalities, Hong Kong and Macao special administrative regions and part of Liaoning, Hebei, Shandong, Jiangsu, Zhejiang, Fujian, Guangdong and Guangxi provinces (Fig. 1).

\subsection{Data and processing}

Remote sensing data include Landsat TM/ETM+ images (59 scenes in 2000, 52 scenes in 2005 and 62 scenes in 2010), downloaded from United States Geological Survey (USGS) global visualization viewer (http://glovis. usgs.gov/). Landsat TM/ETM+ images were all captured in the growing season, with a good quality (total cloud cover $<5 \%$ ). According to previous researches on land use changes in coastal zone (Dobson et al., 1995; European Environment Agency, 1995; Hou and Xu, 2011; Gao et al., 2011; Sun et al., 2012), we improve the classification system of land use in China's coastal zone. In detail, it includes farmland, forest, grassland, city, rural settlement, isolated industrial-mining, inland freshwaters, coastal saltwater, saltern, mariculture, unused land and shallow water. This classification system takes consideration of both land and sea regions at the national coastal zone, and puts an emphasis on the wetland subdivisions (Ramsar Convention on Wetlands, 1971; Gao et al., 2010; Cai et al., 2012). 


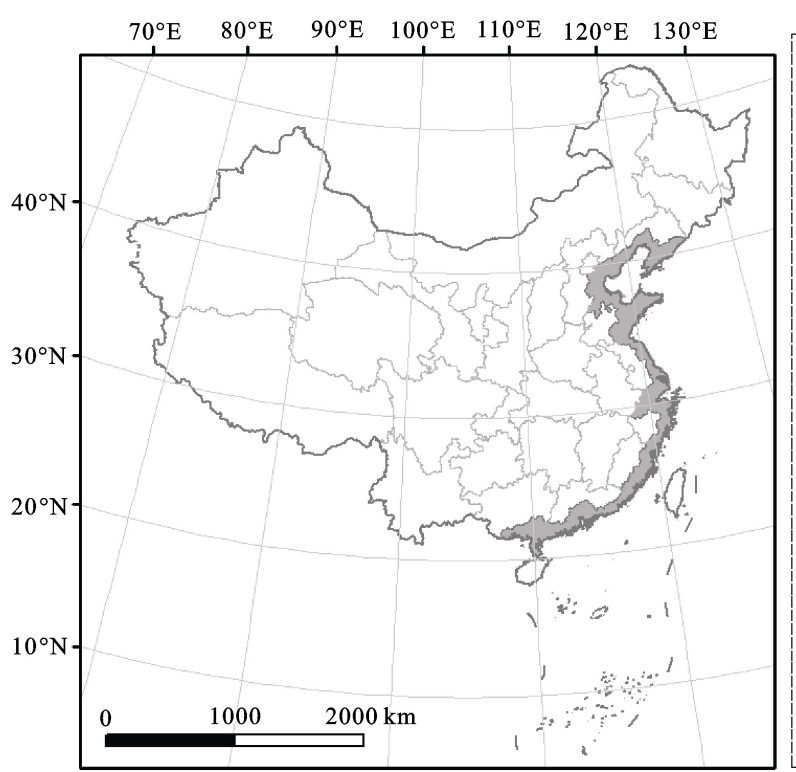

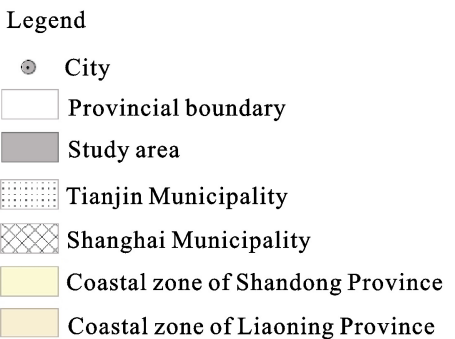
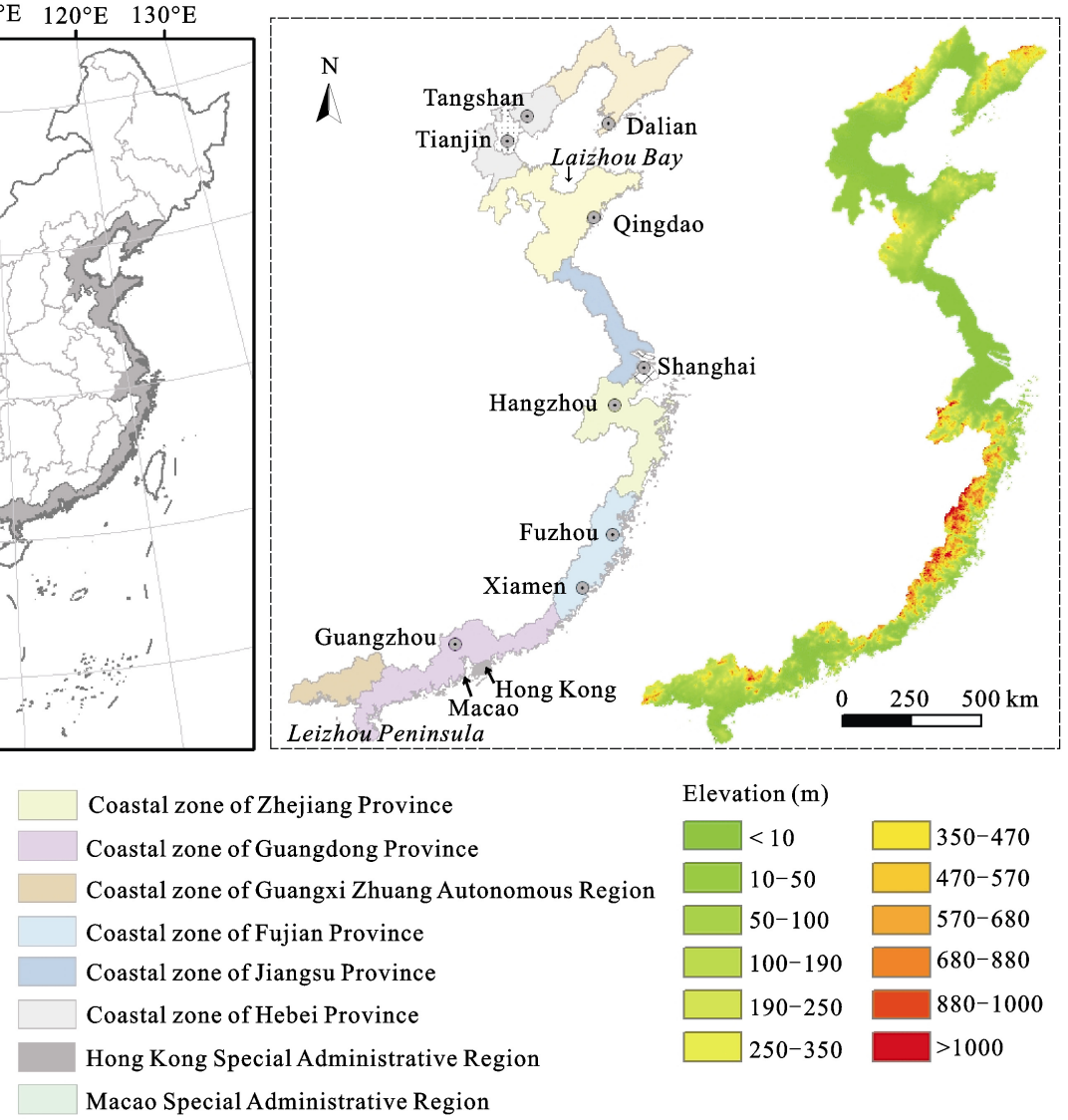

Fig. 1 Location, districts and terrain of study area

Due to significant diversity, complexity and regional discrepancy of coastal land uses in China, automatic classification method can not guarantee the land use mapping accuracy at a large scale. Therefore, visual interpretations are carried out on remote sensing images to produce land use maps in ArcMap 9.3 environment at scale of 1:100 000 in this paper. Furthermore, reference materials including ground-truthing data, Google images, DEM data, vegetation maps, topographic maps, historical land use maps, are utilized to provide auxiliary information for classification accuracy controls. The original land use map of 2000 comes from the Land Use Database in China at the scale of 1:100 000 (Institute of Geographic Sciences and Natural Resources Research, Chinese Academy of Sciences), and its accuracy is more than 95\% (Liu et al., 2003). Subsequently, we modified the data based on Landsat ETM+ images of 2000 according to the new classification system. The dynamic information of land use is detected by comparison of images of 2000 and 2005 at first, and then land use map of 2000 is updated to get the land use data of 2005. The overall precision of land use map is above
$95 \%$, which testified by out-door surveys during 2007-2008 and Google earth information. The same work flow is applied to the land use data of 2010.

\subsection{Methods}

Comprehensive index of land use intensity was used to express the land use intensity quantitatively, which could be calculated as follows (Zhuang and Liu, 1997).

$L=100 \times \sum_{i=1}^{n} C_{i} \times A_{i} \quad L \in[100,400]$

where $L$ is land use intensity comprehensive index in a certain region; $A_{i}$ is the grade index of land use type $i ; C_{i}$ is the area percentage of land use type $i ; n$ is the number of land use types.

According to the influence degree of human activities, land use can be divided into four levels with corresponding grade index (Liu et al., 2005), in which unused land and shallow water are assigned a factor value of 1 ; forest, grassland, inland freshwaters and coastal saltwater are assigned a value of 2; farmland, saltern and mariculture are assigned a value of 3 ; and city, rural set- 
tlement and isolated industrial-mining are assigned a value of 4 .

Land use change results in temporal variations of land use intensity, therefore, the changing trend of land use intensity comprehensive index can quantitatively reveal the development characteristics of regional land utilization, which is expressed as follows (Liu et al., 2005):

$\Delta L_{b-a}=L_{b}-L_{a}$

where $L_{b}$ and $L_{a}$ are the land use intensity comprehensive indices in time points of $b$ and $a$, respectively. If $\Delta L_{b-a}>0$, the land use is in the stage of developing; otherwise, the land use is in the stage of adjusting or regressing.

In this paper, in order to reveal the spatial-temporal dynamics of land use intensity, we transformed the land use vector map into grid dataset of land use at $1 \mathrm{~km}$ scale firstly, and then calculated land use intensity comprehensive index at $1 \mathrm{~km}$ scale by Equation (1). The creation of structural grid dataset of land use at $1 \mathrm{~km}$ scale is as follows: Firstly, to create a fishnet at scale of $1 \mathrm{~km}$. Secondly, to combine the land use vector map of a specific period with the fishnet to calculate the area of each land use type in each grid cell. Thirdly, to record the area of a certain kind of land use with a grid data layer at $1 \mathrm{~km}$ scale. Therefore, the land use vector map of each single period is converted into structural grid dataset of land use at $1 \mathrm{~km}$ scale among which a raster map layer records the area of one land use type.

\section{Results and Analyses}

\subsection{Spatial-temporal characteristic of land use in-} tensity in coastal zone

There is a significant spatial distinction in land use intensity between the north and south coastal zones in China (Fig. 2). Generally, it is divided into two parts by the line of Hangzhou-Jiaxing-Huzhou Plain-Ningshao Plain. The land use intensity is much higher in the north (including Hangzhou-Jiaxing-Huzhou Plain and Ningshao Plain), except the mountainous and hilly areas, and it is lower in the south, except the river delta and low plain regions. What's more, the overall spatial pattern of land use intensity at macro spatial scale remains stable during 2000 and 2010.

During 2000 and 2005, there was a dramatic growth in metropolitan areas, such as Tianjin-Tangshan region, Changjiang (Yangtze) River Delta (in and around Shanghai Municipality), Fuzhou-Quanzhou-Xiamen region, Zhujiang (Pearl) River Delta (in and around Guangzhou City), and northern Laizhou Bay (Fig. 3). Meanwhile, a dramatic decrease can be found in the west of Leizhou Peninsula. From 2005 to 2010, the land use intensity continually increased in the northern coastal zone, including Tianjin-Tangshan region, coastal zone of Hebei and Shandong Provinces; but the increase of land use intensity in the south was not that obvious as north, only a small area around Fuzhou City and Guangzhou City presented minimal increasing changes. In addition, an exceptional dramatic decrease of land

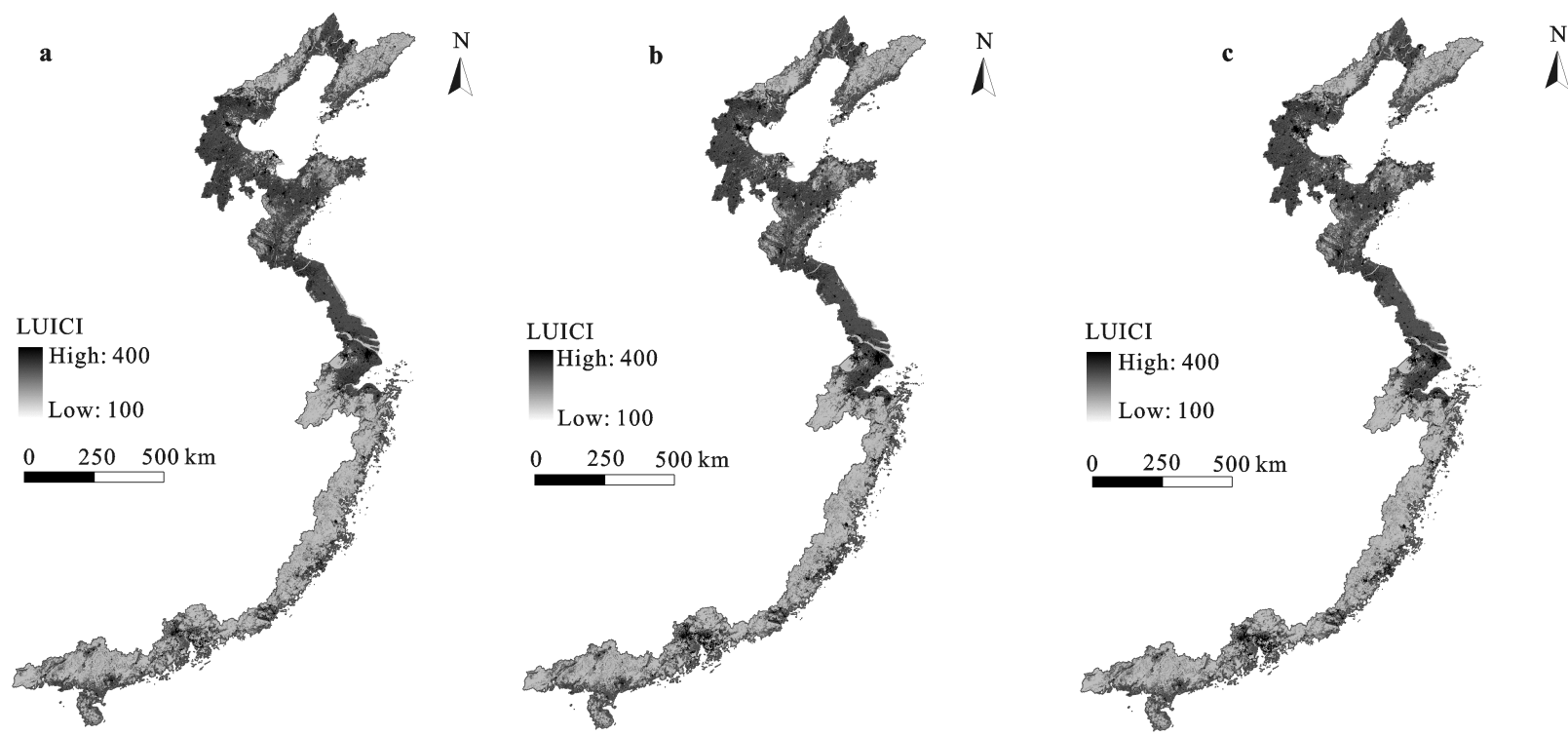

Fig. 2 Spatial patterns of land use intensity comprehensive index (LUICI) in 2000 (a), 2005 (b) and 2010 (c) 

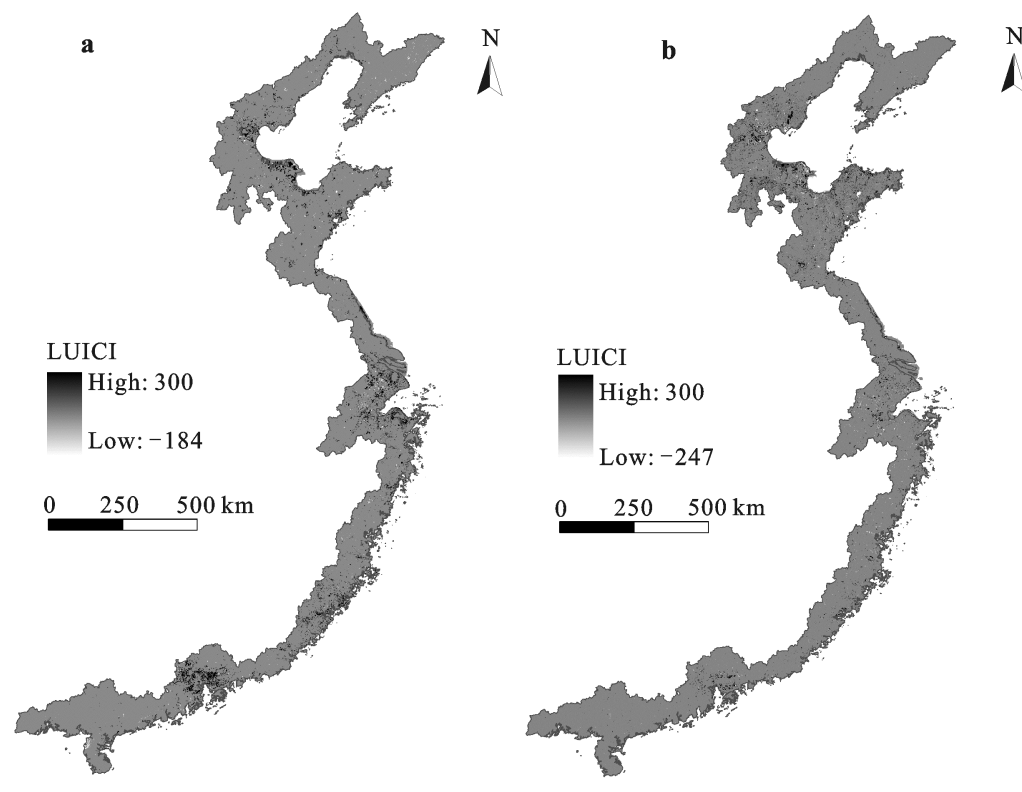

Fig. 3 Land use intensity comprehensive index (LUICI) change from 2000 to 2005 (a) and from 2005 to 2010 (b)

use was seen in the Huanghe (Yellow) River Delta of the western Laizhou Bay.

\subsection{Inter-provincial spatial-temporal discrepancies of land use intensity}

The inter-provincial spatial and temporal discrepancies of land use intensity in China's coastal zone are also found to be significant in this study (Fig. 4). Land use intensity was generally higher in the north, including Hebei, Shandong, Jiangsu, Shanghai and Tianjin, where LUICI were higher than 285; while it is much lower (below 260) in Zhejiang, Fujian, Guangdong and Guangxi provinces along the south coast with the lowest value appeared in Fujian that less than 235. Because of the high proportion $(>60 \%)$ of construction land, the highest value of LUICI appeared in Macao. From 2000-2010, the LUICI of each provincial-level administrative unit in the coastal zone showed an increasing trend, which can be clear seen from 2000 to 2005, while from 2005 to 2010 , LUICI generally remained stable.

\subsection{Elevation differentiation of spatial and tem- poral pattern in land use intensity}

There is significant elevation differentiation in the coastal zone of China, which includes both broad and flat plains, beaches, and steep mountains or hills. Based on $1-\mathrm{km}$ resolution DEM data, the whole terrain of China's coastal zone was separated by equal distance of $10 \mathrm{~m}$ height intervals, and LUICI of three different time phases were extracted for each range of elevation (Fig. 5).

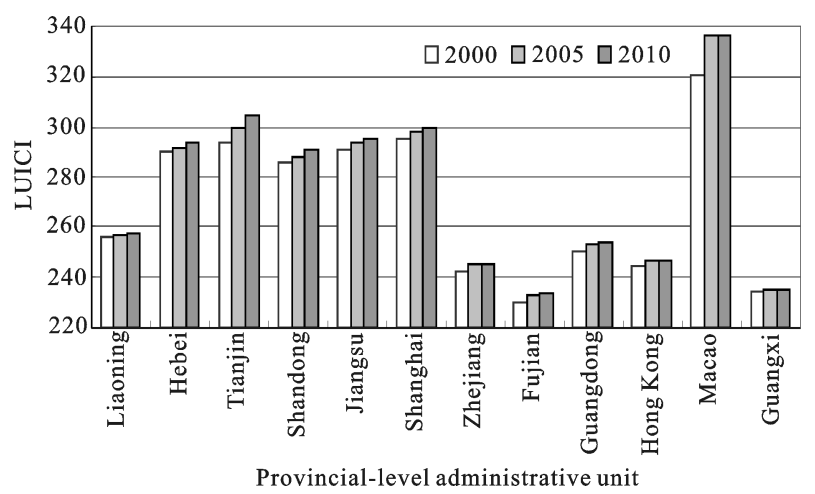

Fig. 4 Changes of land use intensity comprehensive index (LUICI) in different regions

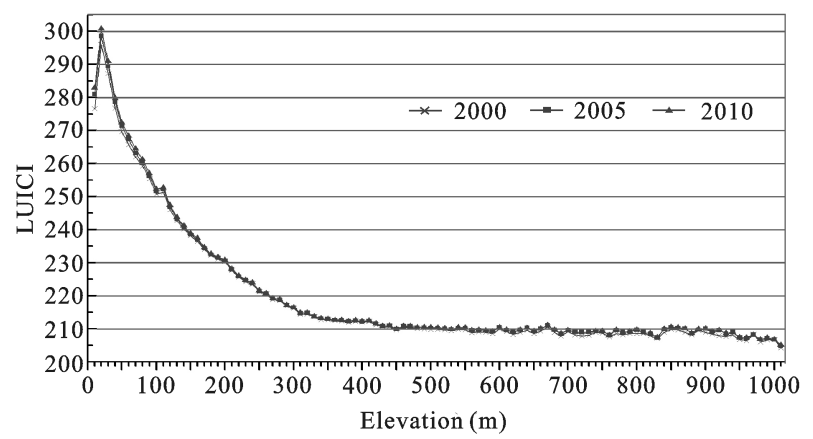

Fig. 5 Average value of land use intensity comprehensive index (LUICI) in different elevation-zones

It is found that the coastal area with the elevation between 10-20 $\mathrm{m}$ has the highest land use intensity, where the value reached 300; the area between $20-30 \mathrm{~m}$ was the second highest with the value of LUICI declined to 
290. Because there are widespread distribution of wetlands and beaches in the area where elevation is lower than $10 \mathrm{~m}$, the average value of LUICI was only about 280. From the perspective of time phases, during 2000-2005, due to massive sea reclamation leading by urban exploitation, the increase of land use intensity in this area was much more significant. The LUICI was continually descending until the elevation reached 400 $\mathrm{m}$, but the responses of land use intensity to elevation decayed markedly where the elevation is above $400 \mathrm{~m}$.

To further analyze the relationship between land use and terrain, the land use intensity was divided into three levels, high-intensity (300-400), medium-intensity (200$300)$ and low-intensity (100-200). Figure 6 showed the distribution of different land use intensity levels in various elevation zones. 1) The highest proportion of high-intensity was beneath $40 \mathrm{~m}$ in 2000, 2005 and 2010, and it decreased sharply when the elevation was above $40 \mathrm{~m}$; besides, it only accounted for less than $1 \%$ where elevation is higher than $300 \mathrm{~m}$. From 2000 to 2010 , the area proportion of high-intensity continually increased in all elevation zones. 2) The highest area proportion of medium-intensity appeared in the area with elevation between $40-400 \mathrm{~m}$ in 2000, 2005 and
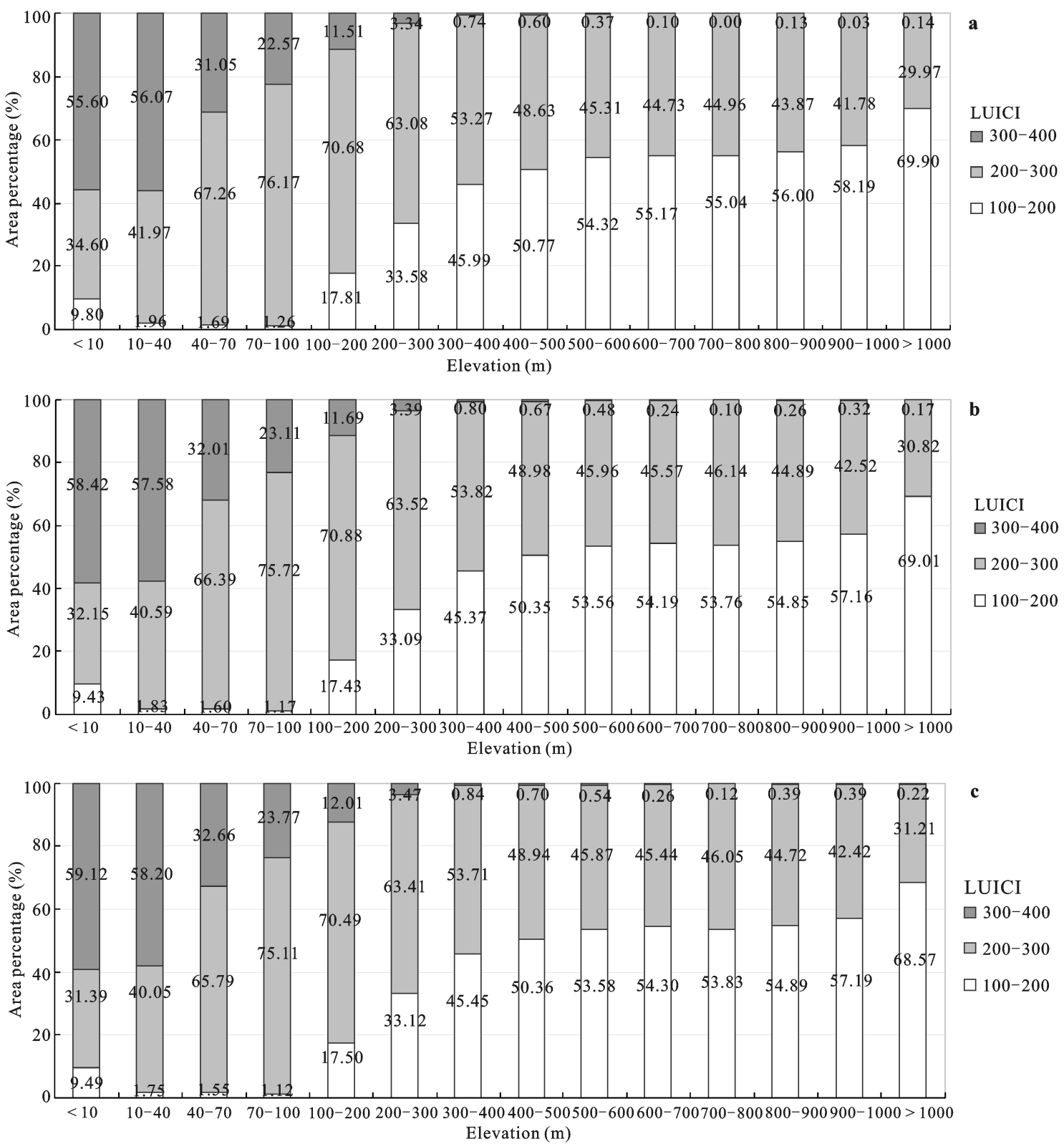

Fig. 6 Area percentages of three grades of land use intensity comprehensive index (LUICI) in different elevation-zones in 2000 (a), 2005 (b) and 2010 (c) 
2010. From 2000 to 2010 , the area proportion of medium-intensity showed a decreasing trend in the areas beneath $100 \mathrm{~m}$, and a sustained growth above $1000 \mathrm{~m}$ elevation. The proportion increased during 2000-2005 and decreased during 2005-2010 in the region where elevation is between $100-1000 \mathrm{~m}$. 3) Low-intensity mainly distributed above $400 \mathrm{~m}$ in 2000, 2005 and 2010, and this proportion increased as elevation increasing. During 2000-2005, the area proportion of low-intensity showed a decreasing trend, however, during 2005-2010, its proportion increased, except the regions between $10-100 \mathrm{~m}$ and above $1000 \mathrm{~m}$.

\subsection{Land-ocean gradient of land use intensity}

Coastline of China's mainland was buffered equidistantly to landward side at an interval of $2 \mathrm{~km}$, and buffer zone from coastline to the sea was regarded as island area. Consequently, we obtained 52 bands of buffer zones and extracted average value of LUICI in different bands (Fig. 7). The land use intensity of island area was the lowest, with an average value less than 160 . The value was only about 240 in the buffer zone that $0-2 \mathrm{~km}$ far away from the coastline, which is basically the lowest region in the mainland zones. Land use intensity increase as distance increased within the region $2-8 \mathrm{~km}$ far away from the coastline, and it reached a peak in the 6-8 km buffer zone. LUICI decreased sharply with distance increasing in the region 8-36 km away from the coastline. However, in the region further than $36 \mathrm{~km}$, LUICI exhibited an obvious fluctuation. During 2000-2010, LUICI has different degrees of growth in all buffer zones; meanwhile, it has a significant stage characteristic at five-year interval.

Figure 8 illustrated area ratios of three levels of land use intensity, including high-intensity (300-400), medium-intensity (200-300) and low-intensity (100-200)

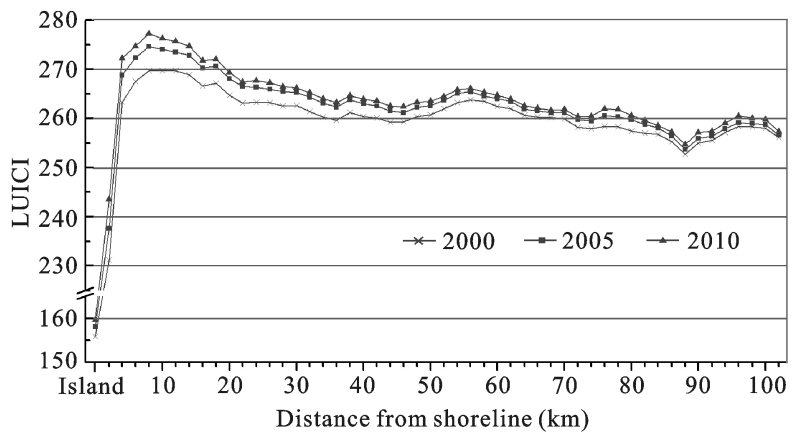

Fig. 7 Average value of land use intensity comprehensive index (LUICI) in different distance from shoreline in different buffer zones. High-intensity mainly concentrated in the region 4-20 km away from the coastline in 2000 and 2005; while in 2010, it concentrated in the region 2-20 km away from the coastline. During 2000-2010, the area proportion of high-intensity increased significantly in all buffer zones. The highest area proportion of medium-intensity occurred in the buffer region $20-30 \mathrm{~km}$ in 2000; while in 2005 and 2010 , its highest proportion was found in the area far away $70-80 \mathrm{~km}$ from the coastline. During 2000-2010, the medium-intensity proportion continued increasing in island area, and decreasing in the mainland buffer zones. The area proportion of low-intensity was more than $70 \%$ in island area. From 2000 to 2005, its proportion declined significantly in all zones, especially in island area and the region $0-40 \mathrm{~km}$ away from the coastline; meanwhile, the proportion showed a fluctuation change in the region further than $40 \mathrm{~km}$.

\section{Discussion}

\subsection{Impacts of natural environment factors on land use intensity}

The close correlation between terrain and land use intensity indicates that elevation has very strong impacts on land use intensity in China's coastal zone. This is mainly due to the law that elevation often determines the accessibility of human activities and the way of human utilization on land resources. Low-flat regions are commonly the main areas with intense human activities and usually have long-term development histories. In these regions, farmland and built-up land are widely spread and the land use intensity is extensively high. While high-elevation regions are mainly dominated by forest, grassland and a small amount of farmland due to the unsuitable natural environment conditions for massive artificial land use activities. Therefore, land use intensity is relatively low in those areas. Northern coastal zone in China contains large plains with gentle terrain, and its primary land use type is farmland; furthermore, it has a bunch of big and small cities, rural settlements and isolated industrial-mining as well. Southern coastal zone in China mainly compose of large area of mountains and hills, and its primary land use types are forests and grasslands, with a low proportion of cities, rural settlements and isolated industrial-mining sites, which normally concentrated in estuarine deltas. 

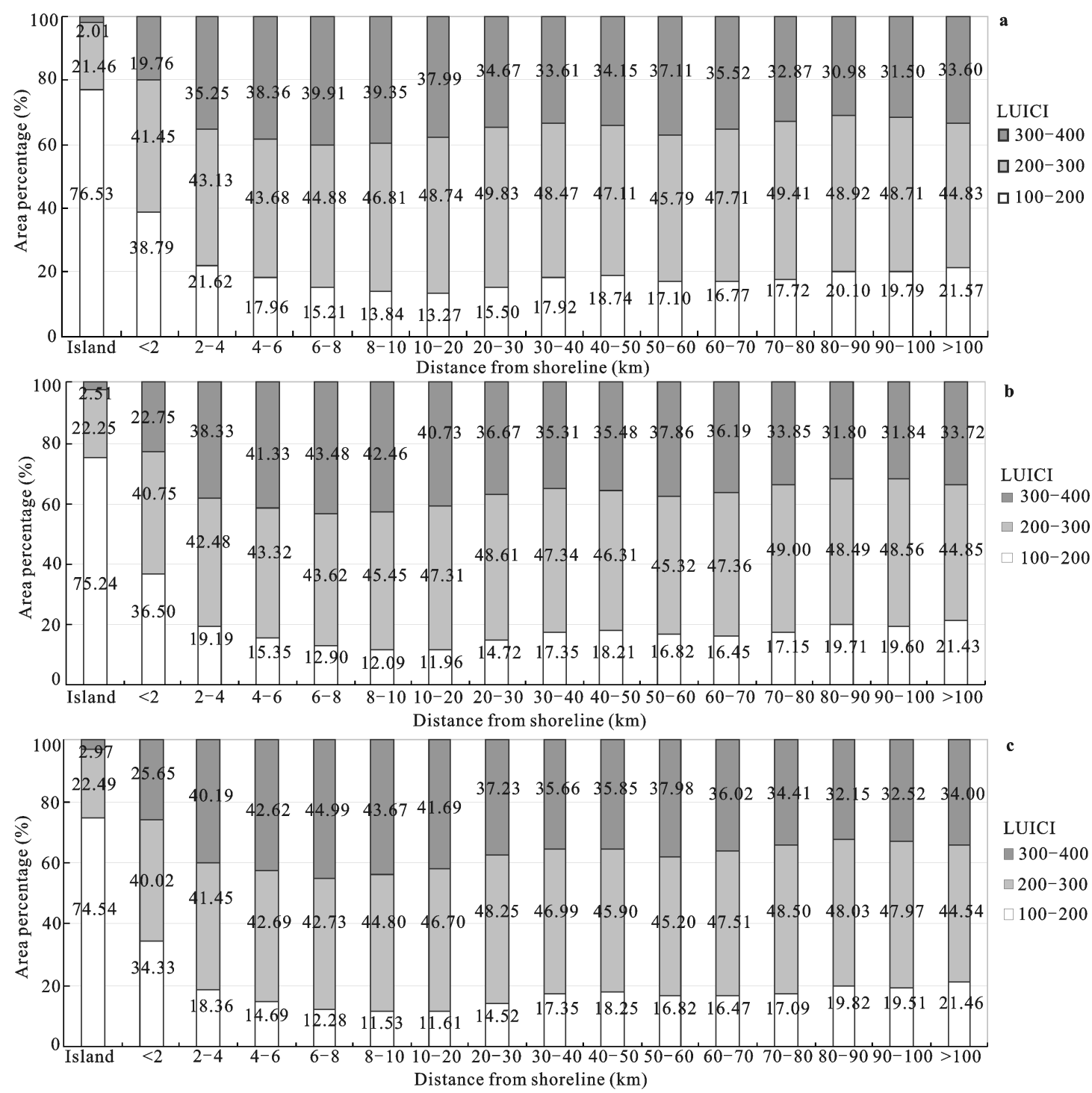

Fig. 8 Area percentages of three grades of land use intensity comprehensive index (LUICI) in different distance from shoreline in 2000 (a), 2005 (b) and 2010 (c)

At macro scale, landform determines the essential features of the spatial pattern of land use intensity, and the land-ocean gradient further influence the spatial pattern of land use intensity. Within low elevation coastal area, most near-shore regions are dominated by large areas of coastal wetlands, tidal flat, lagoons and delta plains, which are easily affected by natural disasters (such as floods, storm surges and typhoon), shoreline erosion and sea water intrusion; therefore, the regional land use intensity is low. For example, affected by coast erosion and salinization during 2005-2010, land loss, saltern and farmland abandonment (mainly converted into grassland and unused land) were significant in the northeastern Huanghe River Delta, which lead to an ob- vious decrease of regional land use intensity.

\subsection{Impacts of socio-economic factors on land use intensity}

As mentioned above, natural environment factors determine the fundamental spatial patterns of land use intensity at macro spatial scale; while socio-economic development is the major driving factor of land use intensity change at multi-scale. The stimulating effects of market economy had strong impacts on land resources utilization, which drives land use changes widely and greatly and, most often, lead to the significant increasing of land use intensity. Land use policies promulgated by central and regional government have put great empha- 
sis on farmland protection and ecological land protection, which suppressed the growth rate of built-up area and the increasing speed of land use intensity. Fast urbanization has been a significant feature of socialeconomic development in China since the late 1970s. The study area covers the most developed three metropolitan areas in China, which are Beijing-TianjinTangshan metropolitan area, Changjiang River Delta metropolitan area and Zhujiang River Delta metropolitan area. From 2000 to 2005, fast urbanization in and around the three metropolitan areas leaded to an obvious increase of land use intensity.

The temporal variation of land use intensity necessarily go with land use change. Therefore, the development stage of regional land resource utilization determines the changing tendency of land use intensity. For example, in the Huanghe River Delta, unused land transformed into grassland and farmland, grassland transformed into farmland, reservoir and ponds transformed into mariculture; therefore, land use intensity increased remarkably. However, in some mountainous area in the southern coastal regions, most laboring population moved to cities and towns to gain the higher economic income, which led to the farmland abandonment and the decreasing of land use intensity.

From 2000 to 2005, in near-shore regions, large areas of shallow water and wetlands transformed into saltern, mariculture, and lots of ports were constructed or real estate area were developed. Meanwhile, in regions far from the shoreline, industrialization and urbanization prompted large areas of forest, grassland and farmland to transform into built-up area. Therefore, the area proportion of high-intensity increased in all elevation-zones and buffer-zones, while area proportion of medium-intensity and low-intensity significantly decreased. From 2005 to

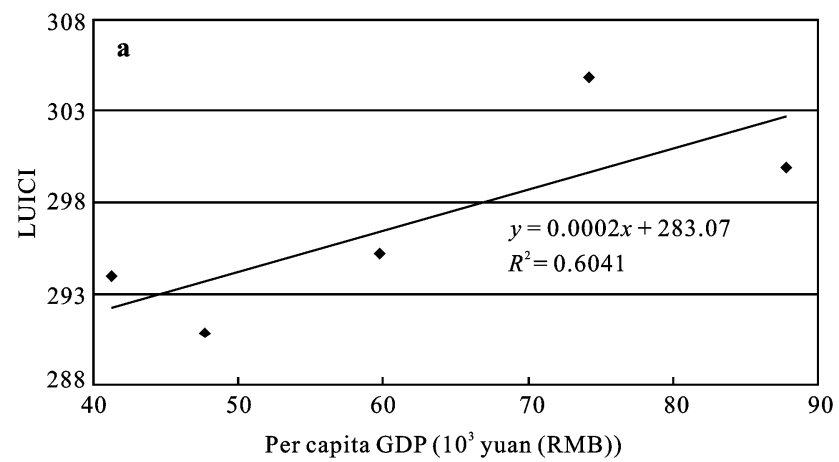

2010, medium-intensity and low-intensity area of land use went on transforming into high-intensity in near-shore region. However, benefited from the stringency of policies aiming to farmland and ecological land protection, remarkable achievements have been made in ecological restoration of forest and grassland in high elevation regions which led to the growth phenomena of low-intensity; meanwhile, the magnitude of urbanization and infrastructure construction has been restricted. Therefore, the growth of land use intensity during 2005-2010 was obviously inferior to that during 2000-2005.

It is worthwhile to be noticed that land use intensity in different provincial-level administrative units exhibited obvious distinctions, even under similar natural environmental conditions. Therefore, we divided the study area (except Hong Kong and Macao for their special relationships between social-economic development and land use condition comparing with other provincial-level administrative units in mainland of China) into two groups to analyze the relationships between the per capita GDP and LUICI by using a linear fit method: the first one is the low-elevation coastal regions, including coastal area in Hebei, Shandong, Jiangsu, Shanghai and Tianjin; and another one is the high-elevation coastal regions, including coastal area in Liaoning, Zhejiang, Fujian, Guangdong and Guangxi. The results show that the overall trend in the low-elevation coastal regions are rising and has a goodness of fit $\left(R^{2}=0.6041\right)$ (Fig. 9a). Meanwhile, it also shows rising trend and has a goodness of fit $\left(R^{2}=0.6500\right)$ in the high-elevation coastal regions (Fig. 9b). The results of the two groups both show that there is a positive correlation between land use intensity and per capita GDP, which affirms that the variation of land use intensity was significantly affected by socioeconomic factors.

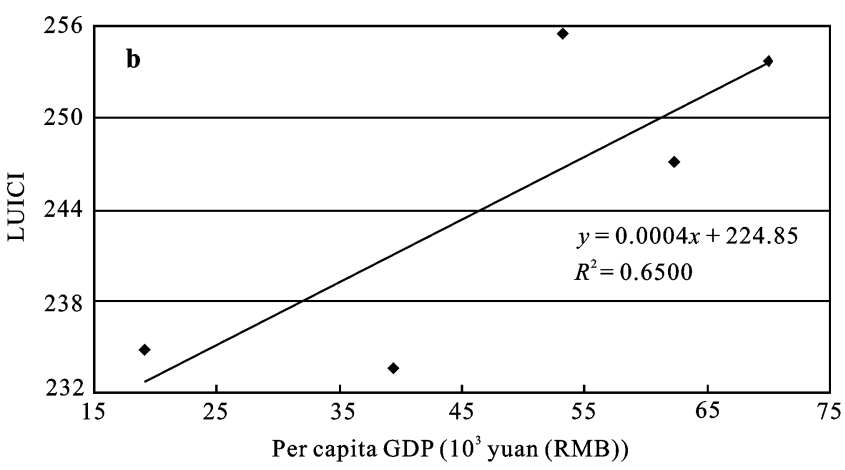

Fig. 9 Relationship between land use intensity comprehensive index (LUICI) and per capita GDP in coastal areas of Hebei, Shandong, Jiangsu, Shanghai, Tianjin (a), and Liaoning, Zhejiang, Fujian, Guangdong, Guangxi (b) in 2010 


\section{Conclusions}

This paper investigated the spatial-temporal characteristics of land use intensity in the coastal zone of China from 2000 to 2010 based on land use intensity comprehensive index, and discussed the major factors that have impact on spatial-temporal changes of land use intensity.

There is an obvious distinction in the spatial pattern of land use intensity between the northern and southern coastal area in China because, divided by the line of Hangzhou-Jiaxing-Huzhou Plain-Ningshao Plain, land use intensity is generally high in the north while low in the south. Elevation is a key factor that controls the spatial patterns of land use intensity at macro spatial scale. Land use intensity was higher (mainly the regions of high and medium intensity) in the region beneath $400 \mathrm{~m}$ elevation, and decreased significantly with the increase of elevation. The land use intensity is high in region 4-30 km away from the coastline, where human activities are much intensive. In addition, the exploration intensity of land resources had been gradually increasing year by year in island area. There is an obvious distinction of land use intensity in different provincial-level administrative units, in which Macao possesses the highest land use intensity, followed by Tianjin and Shanghai. Overall, from 2000 to 2010, it is a development period of land use in China's coast area; however, it shows significant stage characteristics at five-year interval because land resources were developed more rapidly during 2000-2005 than that during 2005-2010.

In brief, there are several factors that affect the spatial-temporal variations of land use intensity in China's coastal zone. Elevation determines the overall spatial patterns of land use intensity at macro spatial scale. While land-ocean gradient is another key factor that has significant impacts on the spatial pattern of land use intensity. Socio-economic development and policy are main driving forces for temporal changes of land use intensity. Economic development stimulates the increasing of land use intensity via urbanization, infrastructure construction and so on; while, policies aiming at the protection of farmland and ecological land suppress the increasing of land use intensity or even lead to its decreasing.

\section{References}

Beatley T, Brower D J, Schwab A K, 2002. An Introduction to Coastal Zone Management. Washington D.C.: Island Press.

Bierschenk A M, Savage C, Townsend C R, 2012. Intensity of land use in the catchment influences ecosystem functioning along a freshwater-marine continuum. Ecosystems, 15(4): 637-651. doi: 10.1007/s10021-012-9536-0

Cai Yuanbin, Zhang Hao, Pan Wenbin et al., 2012. Urban expansion and its influencing factors in natural wetland distribution area in Fuzhou City, China. Chinese Geographical Science, 22(5): 568-577. doi: 10.1007/s11769-012-0564-7

Cui Buli, Li Xiaoyan, Jiang Guanghui et al., 2011. Study on land use/cover in mountain area based on the DEM-Taking the Qinghai Lake Basin as an example. Journal of Natural Resources, 26(5): 87-880. (in Chinese)

Dobson J E, Bright E A, Ferguson R L et al., 1995. NOAA Coastal Change Analysis Program (C-CAP): Guidance for Regional Implementation. NOAA/National Marine Fisheries Service, NOAA Technical Report NMFS, 123.

European Environment Agency (EEA). CORINE Land Cover. http://www.eea.europa.eu/publications/COR0-landcover.

Ferdous N, Bhat C R, 2013. A spatial panel ordered-response model with application to the analysis of urban land-use development intensity patterns. Journal of Geographical Systems, 15(1): 1-29. doi: 10.1007/s10109-012-0165-0

Field J G, Hempel G, Summerhayes C P, 2002. Oceans 2020: Science, Trends and the Challenge of Sustainability. Washington D.C.: Island Press.

Gao Yi, Su Fenzhen, Sun Xiaoyu et al., 2010. On changes in landscape pattern of coastal wetland around the Pearl River Estuary in past two decades. Tropical Geography, 30(3): 215-220. (in Chinese)

Gao Yi, Su Fenzhen, Sun Xiaoyu et al., 2011. A study on driving forces of land use change of Guangdong Province coastal zone and islands in recent 20a. Acta Oceanologica Sinica, 33(4): 95-103. (in Chinese)

Hadley D, 2009. Land use and the coastal zone. Land Use Policy, 26(S1): S198-S203. doi: 10.1016/j.landusepol.2009.09.014

Hepcan Ç C, Turan İ A, Özkan M B, 2011. Monitoring land use change in the Çeşme coastal zone, Turkey using aerial photographs and satellite imaging. Land Degradation \& Development, 22(3): 326-333. doi: 10.1002/ldr.997

Hou Xiyong, Xu Xinliang, 2011. Spatial patterns of land use in coastal zones of China in the early 21 st century. Geographical Research, 30(8): 1370-1379. (in Chinese)

Käyhkö N, Fagerholm N, Asseid B S et al., 2011. Dynamic land use and land cover changes and their effect on forest resources in a coastal village of Matemwe, Zanzibar, Tanzania. Land Use Policy, 28(1): 26-37. doi: 10.1016/j.landusepol.2010.04.006

Krausmann F, Erb K H, Gingrich S et al., 2013. Global human appropriation of net primary production doubled in the 20th century. Proceedings of the National Academy of Sciences of the United States of America, 110(25): 10324-10329. doi: 
10.1073/pnas. 1211349110

Kremer H H, Le Tissier M D A, Burbridge P R et al., 2005. Land-ocean Interactions in the Coastal Zone: Science Plan and Implementation Strategy. IGBP Report 51 / IHDP Report 18. IGBP Secretariat, Stockholm, Sweden.

Lambin E F, Rounsevell M D A, Geist H J, 2000. Are agricultural land-use models able to predict changes in land-use intensity? Agriculture, Ecosystems and Environment, 82(1-3): 321-331. doi: 10.1016/S0167-8809(00)00235-8

Li X Z, Sun Y G, Mander Ülo et al., 2013. Effects of land use intensity on soil nutrient distribution after reclamation in an estuary landscape. Landscape Ecology, 28(4): 699-707. doi: 10.1007/s10980-012-9796-2

Liu J Y, Liu M L, Zhuang D F et al., 2003. Study on spatial pattern of land-use change in China during 1995-2000. Science in China (Series D), 46(4): 373-384. doi: 10.1360/03yd9033

Liu Jiyuan, Zhang Zengxiang, Zhuang Dafang et al., 2005. Study on Remote Sensing Spatial-temporal Information of Land-use Change of China in 1990s. Beijing: Science Press. (in Chinese)

Macchi L, Grau H Ricardo, Zelaya P V et al., 2013. Trade-offs between land use intensity and avian biodiversity in the dry Chaco of Argentina: A tale of two gradients. Agriculture, Ecosystems and Environment, 174: 11-20. doi: 10.1016/j.agee.2013. 04.011

Mattheus C R, Rodriguez A B, McKee B A et al., 2010. Impact of land-use change and hard structures on the evolution of fringing marsh shorelines. Estuarine, Coastal and Shelf Science, 88(3): 365-376. doi: 10.1016/j.ecss.2010.04.016

Quan B, Römkens M J M, Bingner R L et al., 2013. Changes in spatiotemporal land use patterns in selected hydrogeomorphic areas of China and the USA. International Journal of Geosciences, 4(3): 537-548. doi: 10.4236/ijg.2013.43049
Sun Yongguang, Li Xiuzhen, He Yanlong et al., 2012. Impact factors on distribution and characteristics of natural plant community in reclamation zones of Changjiang River estuary. Chinese Geographical Science, 22(2): 154-166. doi: 10.1007/ s11769-011-0475-z

Teixido A L, Quintanilla L G, Carreño F et al., 2010. Impacts of changes in land use and fragmentation patterns on Atlantic coastal forests in northern Spain. Journal of Environmental Management, 91(4): 879-886. doi: 10.1016/j.jenvman.2009. 11.004

The Ramsar Convention on Wetlands. Classification System for Wetland Type. http://www.ramsar.org/cda/en/ramsar-documentsguidelines-classification-system/main/ramsar/1-31-105_4000_0_

Wang S Y, Liu J S, Ma T B, 2010. Dynamics and changes in spatial patterns of land use in Yellow River Basin, China. Land Use Policy, 27(2): 313-323. doi: 10.1016/j.landusepol.2009. 04.002

Wang Xiulan, 2000. Analysis on demographic factors and land use/cover change. Resources Science, 22(3): 39-42. (in Chinese)

Zhou W, Wang C, Song X et al., 2011. The quantitative analysis of land use structure characteristics of county in mountainous areas in Sichuan Province of China-A case study of Rong County. Asian Agricultural Research, 3(5): 28-33.

Zhuang Dafang, Liu Jiyuan, 1997. Study on the model of regional differentiation of land use degree in China. Journal of Natural Resources, 12(2): 105-111. (in Chinese)

Zhuang Dafang, Liu Jiyuan, Liu Mingliang, 1999. Research activities on land-use/cover change in the past ten years in China using space technology. Chinese Geographical Science, 9(4): 330-334. doi: 10.1007/s11769-999-0006-3 